University of Nebraska - Lincoln

DigitalCommons@University of Nebraska - Lincoln

Faculty Publications, Department of Psychology

Psychology, Department of

October 1999

\title{
Consistency and Development of Prosocial Dispositions: A Longitudinal Study
}

\author{
Nancy Eisenberg \\ Arizona State University, nancy.eisenberg@asu.edu \\ Ivanna K. Guthrie \\ Arizona State University \\ Bridget C. Murphy \\ University of Oklahoma \\ Stephanie A. Shepard \\ Arizona State University \\ Amanda Cumberland \\ Arizona State University \\ See next page for additional authors
}

Follow this and additional works at: https://digitalcommons.unl.edu/psychfacpub

Part of the Psychiatry and Psychology Commons

Eisenberg, Nancy; Guthrie, Ivanna K.; Murphy, Bridget C.; Shepard, Stephanie A.; Cumberland, Amanda; and Carlo, Gustavo, "Consistency and Development of Prosocial Dispositions: A Longitudinal Study" (1999).

Faculty Publications, Department of Psychology. 103.

https://digitalcommons.unl.edu/psychfacpub/103

This Article is brought to you for free and open access by the Psychology, Department of at DigitalCommons@University of Nebraska - Lincoln. It has been accepted for inclusion in Faculty Publications, Department of Psychology by an authorized administrator of DigitalCommons@University of Nebraska - Lincoln. 


\section{Authors}

Nancy Eisenberg, Ivanna K. Guthrie, Bridget C. Murphy, Stephanie A. Shepard, Amanda Cumberland, and Gustavo Carlo 
Published in Child Development 70:6 (November/December 1999), pp. 1360-1372. Copyright (o 1999 by the Society for Research in Child Development, Inc. Published by Blackwell Publishing. Used by permission.

\title{
Consistency and Development of Prosocial Dispositions: A Longitudinal Study
}

\author{
Nancy Eisenberg, Ivanna K. Guthrie, Bridget C. Murphy, Stephanie A. Shepard, \\ Amanda Cumberland, and Gustavo Carlo
}

The issue of whether there is consistency in prosocial dispositions was examined with a longitudinal data set extending from ages 4 to 5 years into early adulthood $(N=32)$. Spontaneous prosocial behaviors observed in the preschool classroom predicted actual prosocial behavior, other- and self-reported prosocial behavior, self- reported sympathy, and perspective taking in childhood to early adulthood. Prosocial behaviors that were not expected to reflect an other-orientation (i.e., low cost helping and compliant prosocial behavior) generally did not predict later prosocial behavior or sympathy. Sympathy appeared to partially mediate the relation of early spontaneous sharing to later prosocial dispositions. The results support the view that there are stable individual differences in prosocial responding that have their origins in early childhood.

\section{INTRODUCTION}

For decades, psychologists have discussed and de- bated whether there is such a thing as an altruistic or prosocial personality which is enduring over time and situations (Gergen, Gergen, \& Meter, 1972; Rushton, 1980; Staub, 1974). Piliavin, Dovidio, Gaertner, and Clark (1981) asserted that the search for an altruistic personality was futile. More recently, Batson (1991) expressed doubts that an altruistic personality exists.

Penner and Finkelstein (1998) defined the prosocial personality as "an enduring tendency to think about the welfare and rights of other people, to feel concern and empathy for them, and to act in a way that benefits them" (italics are ours). Thus, the prosocial personality may include other-oriented cognitions and prosocial actions, as well as sympathy. Prosocial behavior generally is defined as voluntary behavior intended to benefit another (Eisenberg, 1986). One type of prosocial behavior is altruism. Altruism commonly is viewed as intrinsically motivated, voluntary behavior intended to benefit another-that is, behavior motivated by concern for others (sympathy) or by internalized values, goals, and self-rewards rather than by the expectation of concrete or social rewards, or the desire to avoid punishment or sanctions (Eisenberg \& Fabes, 1998). Altruism, rather than other sorts of prosocial behaviors, is the essence of the prosocial personality. Unfortunately, it usually is impossible to unequivocally differentiate between altruistic and less lofty modes of prosocial behavior, so measures of prosocial behavior generally are considered indicative of an altruistic personality (Penner, Fritzsche, Craiger, \& Freifeld, 1995; Rushton, Chrisjohn, \& Fekken, 1981).
Empathy often is defined as an emotional reaction elicited by and congruent with another's emotional state or condition (Eisenberg \& Fabes, 1998; Hoffman, 1982). It has been argued that empathic responding can result in either sympathy (concern for another based on the apprehension or comprehension of the other's emotional state or condition), personal distress (an aversive, self-focused emotional reaction to the apprehension or comprehension of another's emotional state or condition), or both (Eisenberg, Shea, Carlo, \& Knight, 1991). It is hypothesized that sympathy involves other-oriented motivation whereas personal distress involves the egoistic motive of alleviating one's own aversive negative state (Batson, 1991).

Today there is a body of research indicating that there are individual differences in prosocial behavior in specific settings or at particular points in time (e.g., see Davis, 1994; Graziano \& Eisenberg, 1997; Penner et al., 1995). Evidence for the premise that there are stable individual differences in the tendency to assist and care about others is still limited however. Two types of data are pertinent: data on the consistency of prosocial behaviors and dispositions across contexts or reporters, and data on stability of prosocial tendencies over time.

Evidence of consistency in prosocial behavior across specific helping opportunities is mixed. Findings of cross-situational consistency are weakest in studies of infants and preschoolers, but are modest for children, adolescents, and adults (Eisenberg \& Fabes, 1998; Graziano \& Eisenberg, 1997). The modest consistency findings noted in studies of this type are not surprising given the diversity of measures of prosocial behavior typically used. In many cases, some measures of pro- 
social behavior used in research are likely to be motivated by other-oriented motives whereas others are not and consistency would be expected only if comparable measures are used at different times.

Research examining consistency of prosocial tendencies across time is rare. Several researchers have reported modest correlations for raters' perceptions of children's prosocial behavior over a year or a few years (e.g., Bar-Tal \& Raviv, 1979; Block \& Block, 1973). Eisenberg et al. (1987) found consistency in elementary schoolchildren's actual donating or helping behavior over 2 years; self- and other-reports of prosocial behavior were correlated over 4 years into adolescence (Eisenberg, Carlo, Murphy, \&Van Court, 1995). Moreover, Davis and Franzoi (1991) obtained a relatively high correlation for high school students' self-reported sympathetic concern over 2 or 3 years, whereas Eisenberg et al. (1995) found evidence of consistency in empathy and sympathy in childhood and adolescence for up to 8 years. In many of these cases, the follow-up information was obtained primarily or solely from self-reports.

There are several reasons to expect consistency in prosocial responding across time. First, theorists have suggested that prosocial behavior and empathy-related responding have a genetic basis (e.g., Wilson, 1975). For example, Hoffman (1981) argued that empathy is the biological substrate for human altruism. Thus, biological factors could account for interspecies and intraspecies variation in prosocial responding. Consistent with this reasoning, evidence of heritability has been obtained in twin studies of empathy-related responding and prosocial behavior (Emde et al., 1992; Loehlin \& Nichols, 1976; Matthews, Batson, Horn, \& Rosenman, 1981; Rushton, Fulker, Neale, Nias, \& Eysenck, 1986; Zahn-Waxler, Robinson, \& Emde, 1992).

Second, there is evidence that both prosocial behavior and empathy are linked to temperamental pre- dispositions such as regulation (e.g., Eisenberg, Fabes, Karbon, et al., 1996; Eisenberg, Fabes, Murphy, et al., 1996; Rothbart, Ahadi, \& Hershey, 1994) that likely have a constitutional basis (albeit influenced by the environment; Rothbart \& Bates, 1998). Prosocial behavior and empathy also may be part of an enduring personality trait (agreeableness; Graziano \& Eisenberg, 1997). If prosocial tendencies are linked to early emerging temperament or personality, one would expect some consistency over time in prosocial behavior because temperament and personality are, by definition, relatively consistent over time.

It also is highly likely that environmental factors contribute to the development of a prosocial disposition. Bergeman et al. (1993) found that agreeableness, which can be viewed as including prosocial tendencies to some degree (Graziano, 1994), was influenced by shared environmental influences. Moreover, numerous parental childrearing practices appear to be associated with the development of prosocial behavior and sympathy (Eisenberg \& Fabes, 1998); thus, continuity in the childrearing environment likely contributes to consistency in prosocial responding over time. Indeed, there is some evidence that parental child-rearing practices at age 5 years predict empathy at age 31 (Koestner, Franz, \& Weinberger, 1990) and that a secure attachment in infancy (likely partly reflecting environmental factors) predicts empathy and prosocial behavior in preschool (Kestenbaum, Farber, \& Sroufe, 1989). In brief, although it is unclear to what degree constitutional and environmental factors contribute to consistency in prosocial tendencies, the combination of these factors may be expected to result in some interindividual consistency in prosocial behavior from childhood to adulthood.

Empathy-related responding has been intimately linked to prosocial behavior, both conceptually and empirically. For many years, philosophers and psychologists have argued that people who experience another's emotional distress or need are likely to be motivated to assist the other person(s) (e.g., Hoffman, 1982; Hume, 1777/1966; Staub, 1979). This link between empathy-related responding and prosocial behavior has been supported empirically; the relation is much clearer, however, when various empathy- related reactions are differentiated (Eisenberg \& Fabes, 1998). In general, sympathy has been positively related to prosocial behavior-especially behavior likely to be based on other-oriented emotions and values - whereas personal distress has been unrelated or negatively related to prosocial behavior (Batson, 1991; Eisenberg \& Fabes, 1991). Moreover, cognitive perspective taking-cognitively taking the role of the other or accessing information from memory to assist in understanding another's situation - has been hypothesized to promote sympathy (Batson, 1991; Eisenberg, Shea, et al., 1991; Hoffman, 1982), and has been linked to prosocial behavior (e.g., Underwood \& Moore, 1982; see also Eisenberg \& Fabes, 1998). Thus, sympathy and perspective taking, and, to a limited degree, empathy, can be considered measures of a prosocial disposition which are expected to motivate altruistic behavior.

The goal of the present study was to examine the degree to which prosocial behavior that is likely to be motivated by other-oriented concern predicts prosocial behavior and attitudes and empathy-related responding over 19 years, and whether sympathetic responding mediated the relation between early prosocial behavior and prosocial behavior at an older age. Observational data were obtained for 32 children on naturally occurring prosocial behavior when they were in preschool. In elementary school and high 
school, participants' prosocial behaviors were assessed using a variety of tasks. In addition, mothers' and self-reports of prosocial behavior were obtained in a number of assessments, and self-reported empathy or sympathy, perspective taking, and personal distress were measured numerous times. In late adolescence and early adulthood, self-reports of empathy-related responding, prosocial behavior, and prosocial-relevant cognitions were obtained, and friends also reported on some of the same aspects of participants' prosocial functioning.

Eisenberg-Berg and Hand (1979) suggested that preschoolers' spontaneous sharing behaviors, which often involve a cost to the child, are more other-oriented than are everyday helping behaviors which generally entail little cost or are performed merely to comply with peers' requests. Consistent with these assertions, they found that spontaneous sharing, but not spontaneous helping or compliant sharing or helping, was associated with higher-level prosocial moral reasoning (Eisenberg-Berg \& Hand, 1979; also see Eisenberg, Pasternack, Cameron, \& Tryon, 1984). Moreover, spontaneous prosocial behavior, but not compliant prosocial behavior, has been correlated with sympathy in young children (Eisenberg, McCreath, \& Ahn, 1988). In other studies, Eisenberg and colleagues have found that preschoolers who have a relatively high rate of responding to peers' requests appear to be those who are nonassertive and, consequently, were targets for peers' requests (Eisenberg, Cameron, Tryon, \& Dodez, 1981; Eisenberg, et al., 1990,1984). Larrieu and Mussen (1986) obtained similar findings with elementary schoolchildren. In contrast, preschool children who have a high frequency of compliant prosocial behavior (and are asked to help or share frequently) seem to be prone to experience personal distress when exposed to another's negative emotion (Eisenberg et al., 1988, 1990).

Moreover, in laboratory studies involving preschool, elementary, or high school students, higher-level (i.e., other-oriented and not hedonistic) prosocial moral reasoning has been associated more frequently with prosocial actions that incur a cost (e.g., donating or volunteering time after school) than with behaviors low in cost (e.g., helping pick up dropped paper clips; Eisenberg, Boehnke, Schuhler, \& Silbereisen, 1985; Eisenberg \& Shell, 1986; Eisenberg et al., 1987). Eisenberg and Shell hypothesized that low-cost behaviors are performed rather automatically, without much cognitive reflection-moral or otherwise. Because sharing usually involves a cost (giving up an object) whereas helping often does not, young children's spontaneous sharing behaviors, but not their compliant sharing or helping or spontaneous helping, were expected to predict prosocial behaviors (especially those involving a cost) and empathy-related responding over time.

\section{METHOD}

\section{Participants}

The longitudinal cohort consisted of 16 females and 16 males (30 White and 2 of Hispanic origin) who had been interviewed nine times previously, at ages $4-5$, $5.5-6.5,7-8,9-10,11-12,13-14,15-16,17-18$, and 1920 years (see Eisenberg et al., 1995; Eisenberg, Miller, Shell, McNally, \& Shea, 1991; Eisenberg et al., 1987). Two additional follow-up studies are discussed in this paper; the 11 testing sessions are hereafter referred to as T1 to T11. The mean ages of the participants at T10 and T11 were 258 months (range $=247-267$ months, or approximately 21-22 years) and 281 months (approximately 23-24 years). The original sample (T1) was 37 children. At that time, this was not intended to be a longitudinal study; thus, families who were initially involved had not committed to a longitudinal study. Four children were lost at T2 (most had moved away), and one child was lost at T3. No participants were lost from T3 to T10; one woman refused any participation at T11 ( $n=31$ at T11). Mean years of maternal and paternal education for this sample (as reported at T8 for the 32 participants) were 16.0 and 17.0, respectively (range $=12-20$ years for both). At age 23-24, 2 participants had junior college degrees, 14 had graduated college (four of these were in graduate school), 1 had some college but did not seem to be in school, 10 were still in college, and 4 were high school graduates with very little or no college education. One woman was a homemaker, 1 participant was in the Peace Corps, 1 was on a religious mission, and 22 reported having jobs outside the home (two manual laborers, one chef, one waitress, two in sales; one in forestry; one chemist; one flight attendant; one hotel auditor; one health care administrator; one police dispatch operator; five low-level employees in business; five middle-level management personnel in industry or small businesses).

\section{Measures}

The measures over the many assessments included observational or experimental assessments of prosocial behavior; self-reports of prosocial behavior, empathy-related responding, perspective taking, and prosocial attitudes/values; mothers' reports of prosocial behavior; and friends' reports of participants' prosocialrelevant behavior/attitudes/values, sympathy, and perspective taking. Because all the measures except those obtained at T10 and T11 have been described in previous publications (Eisenberg et al., 1995; Eisenberg, Lennon, \& Roth, 1983; Eisenberg, Miller, et al., 1991; Eisenberg et al., 1987; Eisenberg-Berg \& Hand, 1979), 
T10 and T11 measures are presented in detail, whereas measures from earlier periods are briefly summarized.

Prosocial Behavior in Preschool

Children were observed by at least two observers in the preschool in random order for a minimum of 70 (a maximum of 113) 2-min timings over 6 to 11 weeks. Six observers coded each instance of three prosocial behaviors:

1. Sharing. The child gives away or allows another temporary use of a material object previously in the child's possession (but not as part of a game, e.g., sharing of tea cups when playing tea was not coded as sharing).

2. Helping. The child attempts to alleviate another's nonemotional needs. For example, the child assists another by giving information, helps another with a task, or offers an object not previously in the giver's possession. (These behaviors were not coded as helping if they occurred as part of cooperative play and involved the completion of a mutual goal.)

3. Offers comfort. The child attempts to alleviate the emotional needs of another, for example, tries to make another feel better when in distress.

Each behavior was coded as having occurred spontaneously, as occurring in response to a verbal or nonverbal request from a peer ("asked for" or compliant prosocial behavior), or as not determined to be spontaneous or not spontaneous. Comforting was very infrequent and was combined with helping (see EisenbergBerg \& Hand, 1979). Thus, the final categories of prosocial behavior were spontaneous sharing, compliant sharing, spontaneous helping, and compliant helping.

Each of the six observers coded with a reliability coder for a minimum of sixty 2-min timings. Percentages of exact agreement for each behavioral category were computed only for 2-min periods in which at least one coder observed prosocial behavior (there were many periods when neither coder observed any prosocial behavior). Mean interrater reliabilities ranged from $75 \%$ to $86 \%$ exact agreement.

\section{Actual Prosocial Behavior in Elementary School}

Donating. At T4 and T5, children had an opportunity to anonymously donate their earnings (eight nickels) to a charity for needy children. At the end of some tasks, children were paid the eight nickels, shown a poster of poor children, and left alone to donate money into a can (containing other money) if they desired (Eisenberg et al., 1987). The number of nickels donated (out of eight) was the index of donating.

Helping. At T6, T7, and T8, when the participants were leaving the laboratory and had been paid, they were given some extra questionnaires and asked to assist the experimenter by filling them out and re- turning them in a stamped envelope. Children were told that they need not help, but that the help would be appreciated. Two indexes of helping were computed: whether the students returned the questionnaires, and whether all parts were completed. These measures were standardized and combined at each time period.

At T4 and T5, children also had an opportunity to assist an adult with low-cost helping tasks such as picking up dropped paper clips. These behaviors were not related to moral judgment in past research, and we have argued that they do not reflect moral behavior. Thus, they were not expected to relate to our target measures of prosocial responding. At T4, the helping measures were how much children helped an adult pick up 75 dropped paper clips for $60 \mathrm{~s}$, and helping an adult pick up toys for $90 \mathrm{~s}$ so other children would not trip and hurt themselves. Latency to helping (of both types) and number of clips or duration of picking up toys were measured. Reliabilities between two observers' timings of seconds for $20-25 \%$ of the sample were .85 or higher (the observer was behind a mirror). At T5, children had an opportunity to help pick up fallen papers for $60 \mathrm{~s}$; again, latency to helping (interrater reliability $=.91$ ) and number picked up were measured. At both time periods, latency scores were reversed and scores for latency and time helping were standardized and combined.

Self-Reported Prosocial-Relevant

Behavior and Cognitions

At T6, T7, and T8, children filled out a 23-item adapted version of Rushton, Chrisjohn, and Fekken's (1981) self-report altruism scale. On a scale ranging from 1 (never) to 5 (very often), children indicated how frequently they engaged in 23 behaviors such as giving money to charity or volunteer work $(\mathrm{a}=36, .90$, and .87 at T6, T7, and T8, respectively; Eisenberg et al., 1995; Eisenberg, Miller, et al., 1991). At T10 and T11, participants filled out a 14-item adapted version of Rushton et al.'s (1981) self-report altruism scale $(a=.85$ and .67 at T10 and T11, respectively; taken from Penner et al., 1995) using the same response scale. This measure overlaps in items with the longer 23- item version of the measure completed at T6 to T8. 
At T9, T10, and T11, self-reported moral behavior was assessed with portions of Weinberger's Adjustment Inventory (WAI; Weinberger, 1991, 1997). Sevenitem versions of the restraint subscales that concerned moral behavior were used and were rated 1 (false) to 5 (true). For T9, consideration for others was used (see Eisenberg et al., 1995, for T9 reliability). Sample items and as for T10 and T11 were as follows: consideration for others ("I often go out of my way to do things for other people," $\mathrm{a}=.78$ and 34 , respectively), and suppression of aggression ("I lose my temper and 'let people have it' when I'm angry," $\mathrm{a}=.76$ and 34 , respectively). Items within each subscale were averaged.

At T10 and T11, several additional measures of prosocial behaviors/cognitions were taken from Penner's instrument (Penner \& Finkelstein, 1998; Penner et al., 1995). These included social responsibility and a care orientation. The subset of 15 items from Schwartz's (1968) social responsibility scale used in the Penner et al. (1995) measure was included, rated 1 (strongly disagree) to 5 (strongly agree) (e.g., "If a good friend of mine wanted to injure an enemy of his/hers, it would be my duty to try to stop him/her; a $=.81$ and .70 at T10 and T11, respectively). In addition, four items reflecting a care orientation (e.g., "I chose alternatives that minimize the negative consequences to other people"; $\mathrm{a}=.81$ at both $\mathrm{T} 10$ and T11) were rated on the same scale as that used for social responsibility (Penner et al., 1995).

\section{Mothers' Reports of Prosocial Behavior}

Mothers rated children's prosocial behavior using a slightly adapted 23-item version of the Rushton et al. (1981) scale at T6, T7, and T8, and the same response scale (Eisenberg et al., 1995; Eisenberg, Miller, et al., 1991). It was very similar to that filled out by the child participants. Alphas could not be computed be- cause mothers frequently used the additional option of "don't know" (Eisenberg et al., 1995; Eisenberg, Miller, et al., 1991).

\section{Friends' Reports of Prosocial Behavior}

At T9, T10, and T11, participants were asked to provide the names of friends who might be willing to fill out short questionnaires about the participants. At T9, friends of 25 participants filled out short questionnaires. At T10, reports from at least one friend were obtained for 28 participants; reports from two and three friends were obtained for 20 and 11 participants, respectively (for a total of 59 friends). At T11, analogous numbers were 24,18 , and 6 (total $=48$ ).
Only nine friends were the same individuals at T10 and T11. Mean lengths of the friendships at T10 and T11 (as reported by friends) were 68 and 86 months, respectively. If reports from more than one friend were obtained, they were averaged across each item on each questionnaire.

At T10 and T11, friends responded to items from the short form of WAI, which contains three items per scale. Items on these subscales were similar to those used in the participant report measures. Alphas at T10 and T11 for the three-item scales were both .88 for consideration of others and .85 and .69 , respectively, for suppression of aggression. Data at T9 on consideration for others were obtained with the same scale $(\mathrm{a}=.77)$. At T10 and T11, friends also reported on participants' social responsibility using 10 of the same items filled out by participants, with slight modifications $(a=.72$ and .85 at T10 and T11, respectively).

\section{Self-Reported Empathy-Related Responding}

Children completed Bryant's (1982) 22-item empathy scale for children at T4, T5, and T6 (Eisenberg, Miller, et al., 1991; Eisenberg et al., 1987; as = .60-.78). This scale likely taps a mix of empathy, sympathy, and personal distress. At T7, T8, T9, T10, and T11, participants responded to the empathic concern (sympathy), perspective taking, and personal distress scales from Davis's $(1983,1994)$ Interpersonal Reactivity Index (see Eisenberg et al., 1995; Eisenberg, Miller, et al., 1991). In addition, 19 children completed and re- turned these scales as part of the helping task at T6 (the Davis subscales are not appropriate for elementary schoolchildren). Definitions and as for the seven- item scales at T10 and T11 are as follows: sympathy (the tendency to experience feelings of warmth and concern for others; $\mathrm{a}=.81$ and .83 , respectively), perspective taking (the tendency to adopt the point of view of others; a $=.82$ and 30, respectively), and personal distress (the tendency to feel unease and discomfort in tense interpersonal settings involving others' needs or emotions; $\mathrm{a}=.76$ and .66 , respectively). Alphas for earlier periods ranged from .73 to .91 (with as for personal distress being the lowest, always in the .70-.79 range). Items were rated from 1 (strongly disagree) to 5 (strongly agree). Items on each scale were averaged (after reversing items if appropriate).

\section{Friends' Reports of Empathy-Related Responding}

At T9, friends responded to the same seven-item sympathy and perspective taking scales as did participants (with slight modifications in wording; $\boldsymbol{a}=.80$ - 
35; Eisenberg et al., 1995). The friends' questionnaire packet at T10 and T11 included the seven sympathy items from the Davis (1983) empathic concern scale plus one additional item ("My friend has a tendency to feel concern for others' misfortunes even when he/ she doesn't know those people personally"; $\mathrm{a}=.89$ and 38 , respectively) and six of the seven perspective taking items (modified slightly from the original Davis, 1983, items for an other-report format; $\boldsymbol{a}=.84$ and .92, respectively). The item dropped from the perspective taking scale seemed particularly difficult for friends to answer ("My friend sometimes tries to understand his/ her friends better by imagining how things look from their perspective").

Data Reduction of Measures of Prosocial and Empathy-Related Responding at T10 and T11

Self-report data. At T10 and T11, there were multiple measures of prosocial behavior and attitudes (besides empathy-related responding): self-reported helping behavior, social responsibility, consideration for others, suppression of aggression, and care orientation. All these measures grouped on the same factor in a principal components factor analysis with a varimax rotation at T10 (absolute value of loadings ranged from .57 to 38 ) and T11 (loadings from .57 to 87). Thus, scores on these measures were standardized and aver- aged (after reversing when appropriate) to form a composite prosocial index at each follow-up. Sympathy, perspective taking, and personal distress-all considered to be related to empathy (Davis, 1983) were kept separate in the analyses. Although this aggregate score contains prosocial behaviors and cognitions, as well as low aggression toward others, it is labeled as self-reported prosocial behavior henceforth.

Friends' reports. The friend measures of a prosocial orientation at T10 (consideration of others, suppression of aggression, and social responsibility) also grouped on a single factor in a principle components factor analysis with a varimax rotation at both $\mathrm{T} 10$ (loadings ranged from .66 to 37) and T11 (loading ranged from .85 to .92). Therefore, the various measures were standardized and averaged at both T10 and T11 to form composite measures of friends' re- ports of participants' prosocial dispositions (hence- forth labeled T10 and T11 friend prosocial measures). Empathy-related variables again were kept separate.

\section{Procedures}

At TI, children were observed for a semester at the preschool. At T2 through T8, mothers and chil- dren came to the laboratory together to participate. At T9, participants usually came to the laboratory by themselves.

At both T10 and T11, participants initially were contacted by phone, if possible; then a packet of questionnaires was sent for the participants to fill out and return (order of questionnaires was randomized). Participants were asked to supply names and ad- dresses of friends, if they were willing to do so, when they returned the questionnaires. Participants were paid for their participation. Friends were sent packets of friend questionnaires and were also paid for their participation.

\section{RESULTS}

Means and standard deviations for the major variables at T10 and T11 are presented in Table 1 (most means for variables from earlier periods are in Eisenberg et al., 1995; Eisenberg, Miller, et al., 1991; Eisenberg et al., 1987).

\section{Prediction of Later Measures from Preschool Prosocial Behavior}

To examine the prediction of later prosocial characteristics and behavior from preschool prosocial behavior, spontaneous sharing, spontaneous helping, compliant sharing, and compliant helping were correlated with the various measures of prosocial behavior and

Table 1 Means and Standard Deviations for Measures of T10 and T11 Prosocial and Empathy-Related Characteristics

\begin{tabular}{|c|c|c|c|c|}
\hline \multirow[b]{2}{*}{ Measure } & \multicolumn{2}{|c|}{$\mathrm{T} 10$} & \multicolumn{2}{|c|}{ T11 } \\
\hline & $M$ & $S D$ & $M$ & $S D$ \\
\hline \multicolumn{5}{|l|}{ Self-reported } \\
\hline Self-reported helping & 2.93 & .59 & 2.92 & .44 \\
\hline Consideration for others & 4.29 & .39 & 4.04 & .60 \\
\hline Suppression of aggression ${ }^{a}$ & 2.32 & .76 & 2.41 & .66 \\
\hline Care orientation & 3.59 & .69 & 3.63 & .72 \\
\hline Social responsibility & 3.29 & .61 & 3.64 & .44 \\
\hline Sympathy & 3.88 & .67 & 4.06 & .57 \\
\hline Perspective taking & 3.62 & .69 & 3.69 & .64 \\
\hline Personal distress & 2.33 & .62 & 2.28 & .51 \\
\hline \multicolumn{5}{|l|}{ Friend-reported } \\
\hline Consideration for others & 4.22 & .79 & 4.26 & .63 \\
\hline Suppression of aggression ${ }^{a}$ & 1.84 & .63 & 1.84 & .70 \\
\hline Social responsibility & 3.36 & .57 & 3.41 & .57 \\
\hline Sympathy & 3.60 & .65 & 3.09 & .72 \\
\hline Perspective taking & 3.35 & .72 & 3.69 & .64 \\
\hline
\end{tabular}

Note: For most measures, $n=32$ and 31 at T10 and T11, respectively. Scores could range from 1 to 5 on all measures.

${ }^{\mathrm{a}}$ High scores indicate more aggression. 
empathy-relevant responding obtained in subsequent years. It was clear that most of the significant correlations between preschool prosocial behavior and later measures of a prosocial disposition were for spontaneous sharing. For spontaneous helping and compliant sharing $(\mathrm{M}=.03$ and $.01, S D=.03$ and .01 , respectively), there were no more significant correlations than would be expected by chance. In contrast, for spontaneous sharing (for the sample of $32, \mathrm{M}=.023$ per 2-min observation, $S D=.02$, range $=0-.08$ ), there were many significant and marginally significant correlations. No significant sex differences were found in any type of preschool prosocial behavior.

The correlations are presented in Table 2. Note that two-tailed tests of significance were used, although specific hypotheses usually were formulated (e.g., that spontaneous sharing was hypothesized to predict later prosocial tendencies). Thus, the significance levels in the correlational analyses tend to be conservative. Spontaneous sharing was at least marginally correlated with costly donating at T4 and T5; self- reported helping at T7; self-reported consideration for others at T9; the prosocial aggregate self-report scores at T10 and T11; mothers' reports of helpfulness at T7 and T8; costly helping at T8; sympathy at T6, T7, T8, T9, and $\mathrm{T} 10$; perspective taking at $\mathrm{T} 8, \mathrm{~T} 9$, and $\mathrm{T} 10$; and friends' reports of sympathy at T9, T10, and T11. Thus, spontaneous sharing in preschool was fairly consistently related to self-reports of prosocial responding and sympathy in late childhood, adolescence, and early adulthood, and sometimes predicted actual prosocial behavior and mothers' reports thereof. Spontaneous sharing was unrelated to self-reported empathy (rather than sympathy) at younger ages, or to self-reported personal distress at any age; and it usually was not related to friends' reports of consideration for others or a prosocial disposition in adult- hood (although it was related to friends' reports of sympathy). Although preschool spontaneous sharing was significantly related to high needs-oriented prosocial moral reasoning and negatively related to hedonistic reasoning at T1 (EisenbergBerg \& Hand, 1979), it generally was unrelated to level of prosocial moral reasoning in later years.

There were fewer findings for compliant helping $(\mathrm{M}$ $=.01, S D=.01$ ) but they formed an interesting pattern. Unexpectedly, children rated high in compliant helping reported at T6, T7, T9, T10, and T11 that they were low in personal distress. Moreover, participants rated high for this type of prosocial behavior were viewed by friends at $\mathrm{T} 9$ as low in perspective taking, sympathy, and consideration for others. How- ever, given that the latter findings were all marginally significant, and that these friend reports were from only one time period (indeed, friend-reported perspective taking was positively related to compliant helping at T11), they may not be statistically reliable.

\section{Mediational Analyses}

In a series of analyses, we examined whether individual differences in sympathy mediate the relation of early spontaneous prosocial behavior to later pro- social tendencies. Sympathy was not assessed with the total sample before T7; thus, we examined whether sympathy at T7 and T8 mediated the relation of T1 spontaneous sharing to $\mathrm{T} 9, \mathrm{~T} 10$, and $\mathrm{T} 11$ prosocial tendencies. Because spontaneous sharing was at least marginally related to self-reported prosocial behavior at T9, T10, and T11 (and not to friend-reported pro- social behavior), we used these indexes of prosocial behavior as the criterion variables in the mediational analyses.

For sympathy to mediate the relation of spontaneous sharing to prosocial tendencies, spontaneous sharing (variable $\mathrm{A}$ ) should predict both the mediator, T7 or $\mathrm{T} 8$ sympathy $(\mathrm{B}$, so $\mathrm{A}+\mathrm{B})$, and the criterion, $\mathrm{T} 9$, $\mathrm{T} 10$, or $\mathrm{T} 11$ prosocial behavior $(\mathrm{C}$, so $\mathrm{A}+\mathrm{C})$. In addition, sympathy (B) should predict prosocial behavior (C, B $+C)$, and the prediction of prosocial behavior (C) from spontaneous sharing (A) should drop to non- significance when both A and B are used as predictors of prosocial behavior simultaneously in a regression equation (whereas B should still be a significant predictor; Baron \& Kenny, 1986). Using regression analyses, we computed the aforementioned equations. Six sets of regression equations were computed: T7 or T8 sympathy was used as a mediator when predicting T9, T10, or T11 prosocial behavior.

As can be seen in Table 3, the aforementioned pattern generally held. Spontaneous prosocial behavior always predicted T9, T10, or T11 measures of prosocial behavior at $p<.08$ (for T7 sympathy and T11 prosocial behavior) or better $(A+C)$. In addition, spontaneous sharing always significantly predicted T7 or T8 sympathy $(\mathrm{A}+\mathrm{B})$ and $\mathrm{T} 7$ or T8 sympathy always predicted subsequent prosocial behavior $(B+C)$. Moreover, when spontaneous sharing and sympathy were entered together to predict T9, T10, or T11 prosocial behavior $(A \& B+C)$, in all cases sympathy, but not spontaneous sharing, was a significant predictor (although it was a marginally significant predictor for T7 sympathy predicting $\mathrm{T} 10$ prosocial behavior).

In five of the six cases in Table 3, the data fully met Baron and Kenny's (1986) criteria for mediation. We also computed MacKinnon and Dwyer's (1994) test of whether the mediation was significant. Using two- 
Table 2 Correlations of Preschool Spontaneous Sharing with Prosocial-Related Measures from Other Assessments

\begin{tabular}{|c|c|c|c|c|c|}
\hline \multirow{3}{*}{$\begin{array}{l}\text { Testing } \\
\text { Session }\end{array}$} & \multirow{3}{*}{$\begin{array}{l}\text { Other Measures of Prosocial or } \\
\text { Empathy-Related Responding }\end{array}$} & \multicolumn{4}{|c|}{ Measure of Prosocial Behavior in Preschool and Adulthood } \\
\hline & & \multicolumn{2}{|c|}{ Spontaneous } & \multicolumn{2}{|c|}{ Compliant } \\
\hline & & Sharing & Helping & Sharing & Helping \\
\hline \multirow[t]{3}{*}{$\mathrm{T} 4$} & Costly donating & $.35^{*}$ & $-.32^{+}$ & -.12 & -.07 \\
\hline & Low cost helping & $.40^{*}$ & -.16 & .07 & .13 \\
\hline & Empathy ${ }^{\mathrm{a}}$ & .09 & -.07 & .14 & -.05 \\
\hline \multirow[t]{3}{*}{ T5 } & Costly donating & $.34^{+}$ & $-.46^{*}$ & -.22 & .07 \\
\hline & Low cost helping & .00 & .17 & -.02 & $.30^{+}$ \\
\hline & Empathy ${ }^{a}$ & .15 & .07 & -.08 & .10 \\
\hline \multirow[t]{7}{*}{ T6 } & Self-reported helping ${ }^{b}$ & .24 & .21 & $.40^{*}$ & .14 \\
\hline & Costly helping & .08 & .17 & .03 & .19 \\
\hline & Mother-reported helpfulness ${ }^{b}$ & .19 & .07 & .13 & .19 \\
\hline & Empathy ${ }^{a}$ & .17 & .18 & .15 & -.13 \\
\hline & Sympathy & $.55^{*}$ & -.36 & .26 & -.04 \\
\hline & Perspective taking ${ }^{c}$ & .33 & .18 & .16 & $.41^{*}$ \\
\hline & Personal distress ${ }^{c}$ & .22 & -.28 & .01 & $-.58^{* *}$ \\
\hline \multirow[t]{6}{*}{$\mathrm{T} 7$} & Self-reported helping ${ }^{\mathrm{b}}$ & $.38^{*}$ & -.10 & $.49^{* *}$ & .08 \\
\hline & Mother-reported helpfulness ${ }^{b}$ & $.46^{*}$ & -.08 & .01 & .12 \\
\hline & Costly helping & .09 & -.10 & .15 & -.30 \\
\hline & Sympathy ${ }^{\mathrm{d}}$ & $.36^{*}$ & -.12 & .29 & -.03 \\
\hline & Perspective taking $\mathrm{d}$ & .22 & -.05 & .27 & .03 \\
\hline & Personal distress ${ }^{\mathrm{d}}$ & .01 & $.31^{+}$ & -.13 & $-.33^{+}$ \\
\hline \multirow[t]{5}{*}{ T8 } & Self-reported helping ${ }^{b}$ & .18 & .07 & $.49^{* *}$ & .21 \\
\hline & Costly helping & $.38^{*}$ & -.10 & -.27 & -.13 \\
\hline & Mother-reported helpfulness ${ }^{b}$ & $.35^{+}$ & -.27 & .07 & .23 \\
\hline & Sympathy $^{d}$ & $.39 * *$ & -.13 & .18 & -.04 \\
\hline & Perspective taking ${ }^{\mathrm{d}}$ & $.48^{* *}$ & .00 & .21 & .15 \\
\hline \multirow[t]{7}{*}{ T9 } & Self-reported consideration ${ }^{e}$ & $.41^{*}$ & .00 & .12 & -.08 \\
\hline & Friend-reported consideration ${ }^{c}$ & .15 & .04 & -.10 & $-.37^{+}$ \\
\hline & Sympathy ${ }^{d}$ & $.41^{*}$ & -.05 & .16 & .11 \\
\hline & Friend-reported sympathy ${ }^{f}$ & $.36^{+}$ & -.19 & -.04 & $-.35^{+}$ \\
\hline & Perspective taking d & $.39^{*}$ & .01 & $.36^{*}$ & .17 \\
\hline & Friend-reported perspective taking $f$ & -.08 & -.02 & -.13 & $-.35^{+}$ \\
\hline & Personal distress ${ }^{\mathrm{d}}$ & .08 & .00 & -.16 & $-.48^{* *}$ \\
\hline \multirow[t]{7}{*}{$\mathrm{T} 10$} & Self-reported prosocial behaviorg & $.45^{* *}$ & -.02 & .06 & .09 \\
\hline & Friend-reported prosocial behavior ${ }^{\text {h }}$ & .18 & -.17 & -.02 & .01 \\
\hline & Sympathy ${ }^{d}$ & $.49^{* *}$ & .05 & -.01 & .10 \\
\hline & Perspective taking & $.41^{*}$ & .08 & .13 & .23 \\
\hline & Friend-reported sympathy ${ }^{f}$ & $.39^{*}$ & -.30 & .05 & -.08 \\
\hline & Friend-reported perspective taking & .19 & -.31 & .17 & .18 \\
\hline & Personal distress ${ }^{\mathrm{d}}$ & .06 & .15 & -.06 & $-.39^{*}$ \\
\hline \multirow[t]{7}{*}{ T11 } & Self-reported prosocial behavior & $.32^{+}$ & .09 & .23 & .17 \\
\hline & Friend-reported prosocial behavior & .15 & -.13 & .07 & .29 \\
\hline & Sympathy & .23 & .04 & .14 & .04 \\
\hline & Perspective taking & .19 & .29 & -.01 & .29 \\
\hline & Friend-reported sympathy & $.36^{+}$ & -.31 & .19 & .20 \\
\hline & Friend-reported perspective taking & .01 & -.20 & -.02 & $.46^{*}$ \\
\hline & Personal distress & .17 & -.02 & -.11 & $-.49^{* *}$ \\
\hline
\end{tabular}

a Using the Bryant (1982) empathy scale.

b Using the adapted Rushton et al. (1981) measure.

'Using Davis's (1983) Interpersonal Reactivity Index for a subsample of 19 children.

dUsing Davis's (1983) empathic concern (for sympathy), perspective taking, or personal distress subscales.

' Using the Weinberger's Adjustment Inventory (Weinberger, 1991, 1997) subscale at T9.

'Adapted from Davis's (1983) empathic concern (for sympathy) or perspective taking subscales.

g At T10 and T11, this was an aggregate score of self-reported helping, consideration of others, social responsibility, suppression of aggression, and care orientation.

' This was an aggregate score of friends' reports of participants' consideration of others, suppression of aggression, and social responsibility. ${ }^{*} p<.05 ;{ }^{* *} p<.01 ;{ }^{* * *} p<.001 ;{ }^{+} p<.10$. 


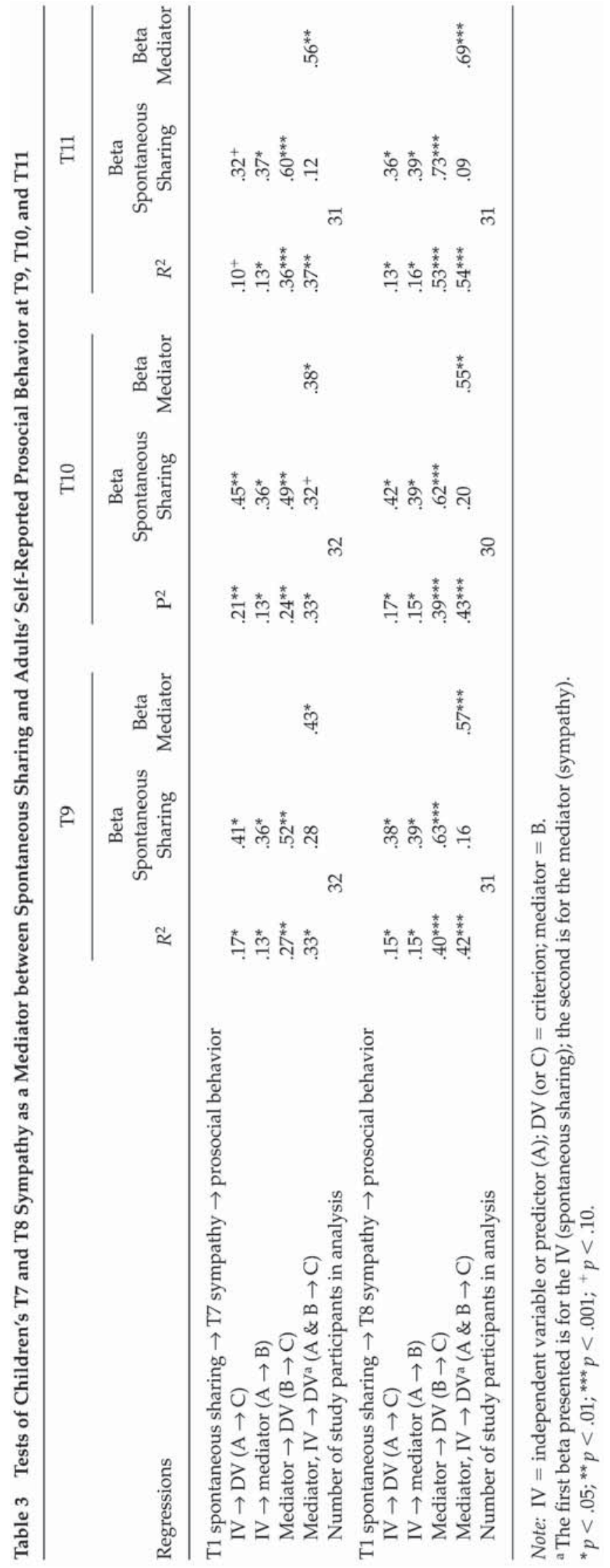

tailed tests, mediation was marginally significant for T7 sympathy predicting T9 and T11 prosocial behavior, $z=1.65$ and $1.81, p<.10$ and .07 , respectively, as well as T8 sympathy predicting T9 and T10 prosocial behavior, $z=1.91$ and $1.92, \mathrm{p}<.057$ and .055 , respectively. Mediation was significant for T8 sympathy predicting T11 prosocial behavior, $z=2.07, \mathrm{p}<.05$. Thus, using this stringent test, there was evidence for some mediation of the effects of early spontaneous sharing on later prosocial behavior.

To test the alternative hypothesis that prosocial behavior in elementary school mediates the relation between early prosocial behavior and later sympathy, similar analyses were conducted to test whether children's reports of helping at $\mathrm{T} 7$ or T8, mothers' reports of helping at T7 or T8, or costly helping at T8 mediated the relation between spontaneous sharing and sympathy at T9, T10, or T11. Mediation was not found in any of these cases.

\section{DISCUSSION}

The results of this study support the view that there is a prosocial personality disposition that emerges early and is somewhat consistent over time. Spontaneous sharing in the preschool classroom, the type of preschoolers' prosocial behavior viewed as involving other-oriented motivation (Eisenberg et al., 1984; Eisenberg-Berg \& Hand, 1979), predicted prosocial behavior/cognitions and empathy-related responding up to 17 years later. Sympathy, including friends' reports of sympathy, was especially linked to early spontaneous sharing and appeared to partially mediate the relation of spontaneous sharing to later prosocial behavior. The mediational effects were likely due to the fact that preschoolers who shared spontaneously were prone to sympathy. Such an assumption is consistent with the fact that preschoolers' spontaneous prosocial behavior was significantly related to their moral judgments involving references to others' needs at that early age.

It is likely that the stability in markers of a prosocial disposition is due to a number of factors. These include temperamental and/or genetic contributions to empathy-related responding (Eisenberg, Fabes, Karbon, et al., 1996; Eisenberg, Fabes, Murphy, et al., 1996; Rothbart et al., 1994), as well as continuity of socialization influences that affect prosocial behavior. Although it is difficult to discern the degree of biological and environmental contributions to the pattern of findings, it is likely that dispositional differences in sympathy, inhibitory control, and a more general other-orientation underlie the variation among people in their prosocial responding from childhood to adult- hood. Even among 
two- and three-year-olds, prosocial behavior often seems to be motivated by empathy or sympathy (ZahnWaxler et al., 1992; see Radke- Yarrow, Zahn-Waxler, \& Chapman, 1983). As early as 4 to 6 years of age, children differ considerably in their reasoning about prosocial and related moral conflicts, and these differences are linked to prosocial behavior (Eisenberg \& Shell, 1986; Eisenberg-Berg \& Hand, 1979) and to the ability to inhibit behavior in the toddler and preschool years (Kochanska, Murray, \& Coy, 1997). Preschoolers' moral cognitions also have been linked to behaviors reflecting individual differences in conscience (Kochanska, Padavich, \& Koenig, 1996). Thus, even by preschool, there seem to be emotional, cognitive, and regulatory under-pinnings to individual differences in prosocial responding. Because moral and prosocial behaviors often require self-control and self-denial, it is logical that the ability to regulate one's own behavior is intimately involved in the development of prosocial behavior. Inhibitory control is viewed as an aspect of temperament with some constitutional basis (Rothbart \& Bates, 1998); yet it is likely that socialization also affects children's early regulation of behavior, especially moral behavior, (see Eisenberg \& Fabes, 1998; Kochanska et al., 1996) $)^{1}$

Individual differences in children's prosocial behavior may be based, in part, on differences among children in the relative or combined contributions of emotion, cognition, and regulation to children's responding to others' distress or need (as well as on individual difference $\sim$ in each of these factors). Children seem to have a fairly stable mode of dealing with others' negative emotions by 2 years of age, a style that is still evident for many children by age 7 . Some children's prosocial behavior has a large component of emotional arousal; some approach others' distress with careful cognitive processing; others shut out signals of distress and turn or run away; and still other young children have an aggressive component in their prosocial interactions (e.g., hit the person who made the baby cry; Radke-Yarrow \& Zahn-Waxler, 1984). The combination of dispositional emotionality and regulation has been found to predict both sympathy (Eisenberg, Fabes, Murphy, et al., 1996) and prosocia1 behavior (Eisenberg, Fabes, Karbon, et al., 1996). For example, children who are emotionally reactive and also are emotionally regulated may be especially prone to spontaneous

'At T9 only, we used the WAI scale (eight items, ct $=.77$ ) to assess impulsivity. Self-reported impulsivity was significantly negatively related to children's spontaneous prosocial behavior, $r(30)=-.40, p<, 024$. sharing; children who are emotionally reactive and under-regulated may find expo- sure to others' distress so aversive that they try to shut out the information or leave the situation. Thus, the pattern of individual differences in empathy-related reactions, other-oriented and moral cognitions, and regulation likely contributes to stable patterns of pro- social responding.

The lack of relation between dispositional personal distress and spontaneous sharing is evidence of the importance of distinguishing between sympathy and dispositional personal distress, both of which may stem from empathy. Personal distress, however, was at least marginally negatively related to preschoolers' compliant helping at five points in time. This finding was unexpected because compliant prosocial behavior (helping and sharing combined) generally has been positively related to young children's personal distress reactions to films (Eisenberg et al., 1990; Eisenberg, McCreath, \& Ahn, 1988). Perhaps the difference in findings across studies is due to the use of observed facial personal distress in studies with young children and self-reported dispositional personal distress in this study. Children who experience personal distress may not be aware of their feelings or may wish to deny such feelings. In addition, the relation between compliant prosocial behavior and personal distress found in studies of preschoolers may be due primarily to findings for compliant sharing, not helping (e.g., sharing was much more common than helping in Eisenberg et al., 1988). Thus, preschool children prone to personal distress in laboratory studies may not be those who were high in compliant helping. Indeed, compliant helpers in preschool may have been children requested to help due to their instrumental skills, and individuals with instrumental skills are likely to score low on personal distress as adults due to the nature of the questions on Davis's personal distress scale (e.g., "I sometimes feel helpless when I am in the middle of a very emotional situation").

The fact that preschool spontaneous sharing was positively related to sympathy but not empathy scores is of particular interest. It is possible that the difference in findings was due to empathy being assessed in childhood, whereas sympathy was assessed in adolescence and adulthood. When this study began, there was, to our knowledge, no self-report measure of sympathy for younger children; consequently, only empathy was assessed. Thus, the difference in findings for empathy and sympathy could be due to validity of self-reports of empathy at a younger age versus sympathy at older ages. Nonetheless, both empathy and sympathy (for a subsample) were assessed at T6 (age 11-12 years), and at that age, spontaneous sharing was substantially correlated with sympathy and not em- 
pathy. Moreover, Eisenberg, Shea, et al., (1991) argued that empathy can evoke either sympathy or personal distress, and that only sympathy is reliably associated with prosocial behavior. Our data provide some support for the argument that sympathy, but not empathy, elicits prosocial motivation and action and serves as a mediator between early and later prosocial tendencies.

In summary, the results of this study support the conclusions that there are individual differences in prosocial dispositions, and that these differences emerge by adolescence and are somewhat stable into adulthood. However, although there are consistencies in prosocial responding over time, it is quite possible that prosocial tendencies become more consolidated, and individual differences become more evident, as children grow into adults. As individuals become capable of understanding higher level moral principles and develop sophisticated perspective-taking abilities and a coherent set of values and goals, it is reasonable to expect greater consistency in prosocial responding. This developmental hypothesis merits further attention.

There are several limitations of the present study. The sample in this study was rather small and homogeneous in its composition. Thus, the results may not be generalizable to different socioeconomic or racial/ ethnic groups. Moreover, it is possible that the families who participated were especially helpful or compliant families. In addition, the children in the original study were in only three classes, so their data may not have been entirely independent. Nonetheless, given that many of the findings were obtained despite limited statistical power, it is likely that a number of the correlational findings will be found in larger samples.

\section{ACKNOWLEDGMENTS}

This research was supported by grants from the National Science Foundation (DBS-9208375), National Institute of Mental Health (1R01 HH55052), and Research Scientist Development and Research Scientist Awards from the National Institute of Mental Health (KO2 MH00903 and KO5 M801321), to Nancy Eisenberg. The authors thank the participants in the longitudinal samples, and their friends who provided data. Gratitude also is due to the Tempe, AZ, schools for their earlier participation in this research.

\section{ADDRESSES AND AFFILIATIONS}

Corresponding author: Nancy Eisenberg, Department of Psychology, Arizona State University, Tempe, AZ 85287-1104; e-mail: nancy.eisenberg@asu.edu. Ivanna K. Guthrie, Stephanie A. Shepard, and Amanda Cum- berland are also at Arizona State University. Although at Arizona State University at the time of this study, Bridget C. Murphy is now at the University of Oklahoma, Norman; and Gustavo Carlo is now at the University of Nebraska, Lincoln.

\section{REFERENCES}

Baron, R. M., \& Kenny, D. A. (1986). The moderator-mediator variable distinction in social psychological research: Conceptual, strategic, and statistical considerations. Journal of Personality and Social Psychology, 51, 1173-1182.

Bar-Tal, D., \& Raviv, A. (1979). Consistency in helping- behavior measures. Child Development, 50,1235-1238.

Batson, C. D. (1991). The altruism question. Hillsdale, NJ:

Erlbaum. Bergeman, C. S., Chipuer, H., Plomin, R., Pedersen, N. L., Mc-Clearn, G. E., Nesselroade, J. R., Costa, P. T., \& McCrae, R. R. (1993). Genetic and environmental effects on openness to experience, agreeableness, and conscientiousness: An adoption/twin study. Journal of Personality, 61, 159-180.

Block, J., \& Block, J. H. (1973, January). Ego development and the provenance of thought: A longitudinal study of ego and cognitive development in young children. Progress report for the National Institute of Mental Health (Grant No. MH16080). Berkeley, CA: University of California.

Bryant, B. K. (1982). An index of empathy for children and adolescents. Child Development, 53, 413-425.

Davis, M. H. (1983). Measuring individual differences in empathy: Evidence for a multidimensional approach. Journal of Personality and Social Psychology, 44, 113-126.

Davis, M. H. (1994). Empathy: A social psychological approach. Madison, WI: Brown \& Benchmark.

Davis, M. H., \& Franzoi, S. (1991). Stability and change in adolescent self-consciousness and empathy. Journal of Research in Personality, 25, 70-87.

Eisenberg, N. (1986). Altruistic emotion, cognition and behavior. Hillsdale, NJ: Erlbaum.

Eisenberg, N., Boehnke, K., Schuhler, P., \& Silbereisen, R. K. (1985). The development of prosocial behavior and cognitions in German children. Journal of Cross-Cultural Psychology, 16, 69-82.

Eisenberg, N., Cameron, E., Tryon, K., \& Dodez, R. (1981). Socialization of prosocial behavior in the preschool classroom. Developmental Psychology, 17, 773-782.

Eisenberg, N., Carlo, G., Murphy, B., \& Van Court, P. (1995). Prosocial development in late adolescence: A longitudinal study. Child Development, 66, 911-936.

Eisenberg, N., \& Fabes, R. A. (1991). Prosocial behavior and empathy: A multi-method, developmental perspective. In P. Clark (Ed.), Review of personality and social psychology (Vol. 12, pp. 34-61). Newbury Park, CA: Sage.

Eisenberg, N., \& Fabes, R. A. (1998). Prosocial development. 
In N. Eisenberg (Ed.), W. Damon (Series Ed.), Handbook of child psychology: Vol. 3. Social, emotional, and personality development (5th ed., pp. 701-778). New York: Wiley.

Eisenberg, N., Fabes, R. A., Karbon, M., Murphy, B. C., Wosinski, M., Polazzi, L., Carlo, G., \& Juhnke, C. (1996). The relations of children's dispositional prosocial behav- ior to emotionality, regulation, and social functioning. Child Development, 67, 974-992.

Eisenberg, N., Fabes, R. A., Miller, P. A., Shell, C., Shea, R., \& May-Plumlee, T. (1990). Preschoolers' vicarious emotional responding and their situational and dispositional prosocial behavior. Merrill-Palmer Quarterly, 36, 507-529.

Eisenberg, N., Fabes, R. A., Murphy, B., Karbon, M., Smith, M., \& Maszk, P. (1996). The relations of children's dispositional empathy-related responding to their emotionality, regulation, and social functioning. Developmental Psychology, 32, 195-209.

Eisenberg, N., Lennon, R., \& Roth, K. (1983). Prosocial development: A longitudinal study. Developmental Psychology, 19, 846-855.

Eisenberg, N., McCreath, H., \& Ahn, R. (1988). Vicarious emotional responsiveness and prosocial behavior: Their interrelations in young children. Personality and Social Psychology Bulletin, 14, 298-311.

Eisenberg, N., Miller, P. A., Shell, R., McNalley, S., \& Shea, C. (1991). Prosocial development in adolescence: A longitudinal study. Developmental Psychology, 27, 849-857.

Eisenberg, N., Pasternack, J. F., Cameron, E., \& Tryon, K. (1984). The relation of quality and mode of prosocial behavior to moral cognitions and social style. Child Development, 155, 1479-1485.

Eisenberg, N., Shea, C. L., Carlo, G., \& Knight, G. (1991). Empathy-related responding and cognition: A "chicken and the egg" dilemma. In W. Kurtines \& J. Gewirtz (Eds.),Handbook of moral behavior and development: Vol. 2. Research (pp. 63-88). Hillsdale, NJ: Erlbaum.

Eisenberg, N., \& Shell, R. (1986). The relation of prosocial moral judgment and behavior in children: The mediating role of cost. Personality and Social Psychology Bulletin, $12,426-433$.

Eisenberg, N., Shell, R., Pasternack, J., Lennon, R., Beller, R., \& Mathy, R. M. (1987). Prosocial development in middle childhood: A longitudinal study. Developmental Psychology, 23, 712-718.

Eisenberg-Berg, N., \& Hand, M. (1979). The relationship of preschoolers' reasoning about prosocial moral conflicts to prosocial behavior. Child Development, 50, 356-363.

Emde, R. N., Plomin, R., Robinson, J., Corley, R., DeFries, J., Fulker, D. W., Reznick, J. S., Campos, J., Kagan, J., \& Zahn-Waxler, C. (1992). Temperament, emotion, and cognition at fourteen months: The MacArthur Longitudinal Twin Study. Child Development, 63, 1437-1455.

Gergen, K. J., Gergen, M. M., \& Meter, K. (1972). Individual orientations to prosocial behavior. Journal of Social Issues, 28,105-130.
Graziano, W. G. (1994). The development of agreeableness as a dimension of personality. In C. F. Halverson, Jr., G. A. Kohnstamm, \& R. P. Martin (Eds.), The developing structure of temperament and personality from infancy to adulthood (pp. 339-354). Hillsdale, NJ: Erlbaum.

Graziano, W. G., \& Eisenberg, N. H. (1997). Agreeableness: A dimension of personality. In R. Hogan, J. Johnson, \& S. Briggs (Eds.), Handbook of personality psychology (pp. 795-824). San Diego, CA: Academic Press.

Hoffman, M. L. (1981). Is altruism part of human nature? Journal of Personality and Social Psychology, 40, 121-137.

Hoffman, M. L. (1982). Development of prosocial motivation: Empathy and guilt. In N. Eisenberg (Ed.), The development of prosocial behavior (pp. 281-313). New York: Academic Press.

Hume, D. (1966). Enquiries concerning the human understanding and concerning the principles of morals (2nd ed.). Oxford, UK: Clarendon Press. (Original work published 1777)

Kestenbaum, R., Farber, E. A., \& Sroufe, L. A. (1989). Individual differences in empathy among preschoolers: Relation to attachment history. In N. Eisenberg (Ed.), New directions for child development: Vol. 44. Empathy and related emotional responses (pp. 51-64). San Francisco: JosseyBass.

Kochanska, G., Murray, K., \& Coy, K. C. (1997). Inhibitory control as a contributor to conscience in childhood: From toddler to early school age. Child Development, 68, 263- 277.

Kochanska, G., Padavich, D. L., \& Koenig, A. L. (1996). Children's narratives about hypothetical moral dilemmas and objective measures of their conscience: Mutual relations and socialization antecedents. Child Development, 67, 1420-1436.

Koestner, R., Franz, C., \& Weinberger, J. (1990). The family origins of empathic concern: A 26-year longitudinal study. Journal of Personality and Social Psychology, 58, 709-717.

Larrieu, J., \& Mussen, P. (1986). Some personality and motivational correlates of children's prosocial behavior. Journal of Genetic Psychology, 147, 529-542.

Loehlin, J. C., \& Nichols, R. C. (1976). Heredity, environment, and personality. Austin: University Of Texas Press.

MacKinnon, D. P., \& Dwyer, J. H. (1994). Estimating mediated effects in prevention studies. Evaluation Review, 17, 144-158.

Matthews, K. A., Batson, C. D., Horn, J., \& Rosenman, R. H. (1981). Principles in his nature which interest him in the fortune of others: The heritability of empathic concern for others. Journal of Personality, 49, 237-247.

Penner, L. A., \& Finkelstein, M. A. (1998). Dispositional and structural determinants of volunteerism. Journal of Personality and Social Psychology, 74, 525-537.

Penner, L. A., Fritzsche, B. A., Craiger, J. P., \& Freifeld, T. S. (1995). Measuring the prosocial personality. In J. Butcher \& C. D. Spielberger (Eds.), Advances in personality assessment (Vol. 10, pp. 147-163). Hillsdale, NJ: Erlbaum. 
Piliavin, J. A., Dovidio, J. F., Gaertner, S. L., \& Clark, R. D., 111. (1981).Emergency intervention. New York: Academic Press.

Radke-Yarrow, M., \& Zahn-Waxler, C. (1984). Roots, motives, and patterns in children's prosocial behavior. In E. Staub, D. Bar-Tal, J. Karylowski, \& J. Reykowski (Eds.), Development and maintenance of prosocial behavior: International perspectives on positive behavior (pp. 81-99). New York: Plenum.

Radke-Yarrow, M., Zahn-Waxler, C., \& Chapman, M. (1983). Children's prosocial dispositions and behaviors. In P. H. Mussen (Ed.), Handbook of child psychology: Vol. 4. Socialization, personality, and social development (pp. 469545). New York: John Wiley \& Sons.

Rothbart, M. K., Ahadi, S. A., \& Hershey, K. L. (1994). Temperament and social behavior in childhood. MerrillPalmer Quarterly, 40, 21-39.

Rothbart, M. K., \& Bates, J. E. (1998). Temperament. In N. Eisenberg (Ed.), W. Damon (Series Ed.), Handbook of Child Psychology: Vol. 3. Social, emotional, and personality development (5th ed., pp. 105-176). New York: Wiley.

Rushton, J. P. (1980). Altruism, socialization, and society. Englewood Cliffs, NJ: Prentice-Hall.

Rushton, J. P., Chrisjohn, R. D., \& Fekken, G. C. (1981). The altruistic personality and the self-report altruism scale. Personality and Individual Differences, 2, 1-11.

Rushton, J. P., Fulker, D. W., Neale, M. C., Nias, D. K. B., \& Eysenck, H. J. (1986). Altruism and aggression: The heritability of individual differences. Journal of Personality and Social Psychology, 50, 1192-1198.

Schwartz, S. H. (1968). Words, deeds, and the perception of consequences and responsibility in social situations. Journal of Personality and Social Psychology, 10, 232-242.

Staub, E. (1974). Helping a distressed person: Social, personality, and stimulus determinants. In L. Berkowitz (Ed.), Advances in experimental social psychology (Vol. 7, pp. 293-341). New York: Academic Press.

Staub, E. (1979). Positive social behavior and morality: Vol 2. Socialization and development. New York: Academic Press.

Underwood, B., \& Moore, B. (1982). Perspective-taking and altruism. Psychological Bulletin, 91, 143-173.

Weinberger, D. A. (1991). Social-emotional adjustment in older children and adults: I. Psychometric properties of the Weinberger Adjustment Inventory. Unpublished manuscript, Case Western Reserve University, Cleveland, $\mathrm{OH}$.

Weinberger, D. A. (1997). Distress and self-restraint as measures of adjustment across the life span: Confirmatory factor analyses in clinical and nonclinical samples. Psychological Assessment, 9, 132-135.

Wilson, E. 0.(1975). Sociobiology: The new synthesis. Cambridge, MA: Harvard University Press.

Zahn-Waxler, C., Robinson, J., \& Emde, R. N. (1992). The development of empathy in twins. Developmental Psychology, 28, 1038-1047. 